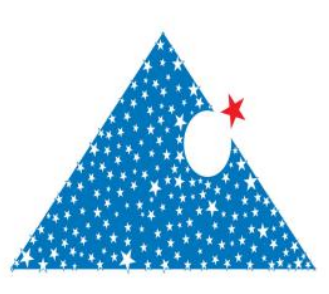

www.dergipark.gov.tr

ISSN:2148-3736

El-Cezerî Fen ve Mühendislik Dergisi

Cilt: 5, No: 3, 2018 (741-748)

El-Cezerî Journal of Science and Engineering

ECJSE

Vol: 5, No: 3, 2018 (741-748)

DOI : $10.31202 /$ ecjse.417791

Makale / Research Paper

\title{
Diş ve İmplant Mikromorfolojik Yapıların Sinyal ve Görüntü İşleme Yöntemleri ile Değerlendirilmesi
}

\section{Pınar DEMİRCIOĞLU}

\author{
Mühendislik Fakültesi, Makina Mühendisliği Bölümü, Adnan Menderes Üniversitesi 09010 Aydın/TÜRKIYYE \\ pinar.demircioglu@adu.edu.tr
}

Received/Geliş: 22.04 .2018

Revised/Düzeltme: 03.07 .2018

Accepted/Kabul: 06.07.2018

\begin{abstract}
Öz : Çalışmanın hedefleri, bir azı diş için bilgisayarda model oluşturmak, orjinal dişin \& implant yüzey karakteristiklerinden olan yüzey pürüzlülüklerini ölçmek ve elde edilen yüksek çözünürlüklü görüntüleri ve sinyalleri işlemektir. Orjinal diş \& implant yüzeyleri, stylus profilometre kullanılarak deneysel olarak ölçülmüştür. 3 boyutlu (3B) dijital mikroskoptan alınan yüksek çözünürlüklü 2B görüntüler ve 1B sinyaller, görüntü işleme tekniği olan 2B hızlı Fourier dönüşümü (FFT) yardımıyla analiz edilmiş ve birbiriyle mukayese edilmiştir. Orjinal diş \& implant yüzeylerinin pürüzlülük sonuçları birbirinden oldukça farklı çıkmıştır. Diğer yandan, stylus profilometreden alınan ölçüm sonuçları görüntü işleme tekniğiyle elde edilen değerler arasındaki korelasyonun son derece yüksek benzerlik göstermiş olduğu görülmüştür. Orjinal diş örneği için, ölçüm hatalarının karelerinin ortalamasının karekökü (RMSE) değeri 0,033 $\mu \mathrm{m}$ olarak hesaplanırken, implant örneği için ise, $0.045 \mu \mathrm{m}$ olarak hesaplanmıştır. Bunun yanında, görüntü analizi sonuçları, FFT analizinin, yüksek korelasyonla (orijinal diş için, $R^{2}=0.94$ ve implant örnek için ise, $R^{2}=0.88$ ) yüzey pürüzlülüğündeki değişkenliği temsil edebileceğini göstermiştir.
\end{abstract}

Anahtar kelimeler: Biyomedikal; pürüzlülük; sinyal işleme; görüntü işleme

\section{Evaluation of Tooth and Implant Micromorphological Structures by Signal and Image Processing Methods}

\begin{abstract}
The aims of this study are to create a model for a molar tooth in computer environment, to measure the surface roughness of original tooth and implant related to surface characteristics and processing the high resolution images and signals which were obtained. Original tooth and implant surfaces were measured experimentally by utilizing stylus profilometer. The high resolution 2D images and 1D signals obtained from 3D digital microscope were analyzed and compared by the help of 2D Fast Fourier Transform (FFT) which is an image processing method. Roughness results of original tooth and implant surfaces were found to be quite different from each other. On the other hand, correlation between measurement results of profilometer and values obtained by image processing technique were found to be very high. Root mean square error (RMSE) of measurement errors was calculated to be $0.033 \mu \mathrm{m}$ for the original tooth sample and $0.045 \mu \mathrm{m}$ for the implant sample. In addition, image processing results have shown that surface roughness variation could be represented by FFT analysis with high correlation $\left(R^{2}=0.94\right.$ for original tooth sample and $R^{2}=0.88$ for implant sample).
\end{abstract}

Keywords: Biomedical; roughness; signal processing; image processing.

\section{Giriş}

Bir diş implantı, bir taç, köprü veya çıkarılabilir protez gibi bir diş protezini desteklemek için çene veya kafatası kemiği ile arayüzleşen bir cerrahi bileşendir. İmplant yerleştirildikten sonra, değişik miktarda iyileşme süresi gereklidir. Biyokompabilite için, bir implantın tasarımı kadar mikromorfolojik yapısı da büyük bir önem teşkil etmektedir. Bu amaçla yüzeylerin pürüzlülüğü, 
implantın mikromekanik tutuculuğunu arttırması açısından kritik bir parametredir. Materyallerin biyokompabilitesi ile beraber, implant tasarımı ve yüzeylerinin mikromorfolojisi gibi etkenlerin optimum düzeyde etkileşimi gerekmektedir.

\section{Literatür Tarama}

Diş implantları üzerine değerlendirilmesi gereken birkaç uluslararası standart bulunmaktadır. BS EN ISO 13485:2016 uluslararası standardının temel amacı, kalite yönetim sistemleri için uyumlu tıbbi cihaz şartlarını oluşturmaktır [1]. BS EN 1642:2011 standardı da aynı zamanda diş implantları için genel şartları belirtmektedir [2]. BS EN ISO 3950:2016, dişler ve ağız boşluğu alanları için düzenleme sistemini ifade etmektedir [3]. DIN EN ISO 16498, klinik kullanım için minimal diş implant veri kümesini tanımlamaktadır [4].

Costa-Berenguer ve arkadaşları, standart çapa sahip $(4.1 \mathrm{~mm})$ dış bağlantılı diş implantlarının kırılma direnci, yüzey pürüzlülüğü ve makroskopik morfolojisi üzerindeki implantoplasti etkilerini araştırmak için çalışmalarını gerçekleştirmişlerdir. Yazarlar ayrıca teknik açıdan külfetli ve zaman gerektiren implantoplastinin standart çaptaki dış bağlantılı implantların kırılma direncini önemli şekilde değiştirdiğinin gözlemlenmediğini belirtmişlerdir [5].

Rupp ve diğerleri, iyileştirilmiş hücresel temas ve diş titanyum implantlarının osseointegrasyonu için belirli bir mikro pürüzlülük değerinin öneminin yanında, yüzey enerjisinin ve 1slanabilirliğin rollerinin öneminin de gittikçe güçlendiğini ifade etmişlerdir. Yazarlar implant / kemik arayüzünde nano boyuttaki topografik özelliklerin ve hidrofilisitenin sinerjik etkilerini de bildirmişlerdir. Sonuç olarak, hidrofilik implantların, başlangıçtaki kan temasını iyileştirmesi, yara iyileşmesini desteklemesi ve böylece osseointegrasyonu hızlandırması kanıtlanmış olduğunu belirtmişlerdir [6].

Babik ve diğerleri, dental implantların üretiminde en çok uygulanan malzemenin farklı saflık derecelerine sahip titanyum olduğunu iddia etmişlerdir. Ve yazarlara göre, ideal biyomateryal olarak önceden belirlenmiş titanyumun diğer özellikleri arasında, titanyumun yüksek mekanik mukavemeti hassas minyatür işleme proseslerini giderek zor hale getirmektedir. Babik ve arkadaşlarının çalışmaları, işleme sonrası diş implantlarının yüzey kalitesi, bütünlüğü ve özellikleri ile ilgilenmektedir [7].

Kournetas ve diğerleri, istatistiksel olarak benzer 3 boyutlu pürüzlülük parametresi sonuçlarını değerlendirmek ve bu verileri önceden belirlenmiş ilgili kriterlere göre faydalı bir biyolojik yanıta dayalı olarak değerlendirmek için taramalı elektron mikroskobu ve optik interferometre araçlarının kabiliyetlerini araştırmışlardır. Ayrıca, iki yöntemin baskın olarak istatistiksel farklılıklar gösterdiğini belirtmişlerdir. Pürüzlülük parametrelerine ve filtre ayarlarına bağlı olarak, her iki yöntem de implant yüzeylerinin sıralamasında farklılıklar göstermiştir ve farklı topografileri ayırt etme yeteneklerine göre de farklılıklar gözlemlenmiştir [8].

Schmidt ve diğerleri, farklı enstrümanlar ve enstrümantasyon sonrasında biyofilm oluşumundan sonra implantların yüzey özelliklerini değerlendirmek için çalışmalarını gerçekleştirmişlerdir. Yazarlara göre, SEM görüntülerinin görsel değerlendirmesi, enstrümantasyonu takiben yüzey modifikasyonlarını (pürüzsüzleştirme ve pürüzlendirme) ortaya çıkarmıştır. Bu değişimlerin, enstrüman gruplarına ve kontrole göre farklılık gösterdiğini eklediler. Fotoğrafların nicel puanlamas1, SSC'nin SP $(\mathrm{P}=0.057)$ ve $\mathrm{PP}(\mathrm{P}=0.108)$ hariç diğer enstrümanlara göre anlamlı derecede daha pürüzlü bir yüzey oluşturduğunu ortaya koymuştur $(\mathrm{P}<0.05)$. Son olarak, çalışmalarına göre, bakteri kolonizasyonundan sonra, her iki kültürde de enstrümantaston ya da kontrol yüzeyleri arasında belirgin bir fark bulunamadığını belirtmişlerdir $(\mathrm{P}>0.05)$ [9]. 
Bosshardt ve arkadaşlarının derlemelerinde, osseointegrasyonun zamansal dizisini ve implant yüzey modifikasyonlarının ve biyomateryalin kimyasal bileşiminin osseointegrasyon üzerindeki etkilerini açıklamayı amaçlamışlardır. Belli implant sistemleri için yüksek başarı ve hayatta kalma oranlarının osseointegrasyonun güvenliğini ve ömrünü doğruladığını ifade etmişlerdir. Diş implantlarının yerleştirilmesi, yazarlara göre kısmen ya da tamamen dişsiz hastaların oral rehabilitasyonu için rutin hale gelmiştir [10].

Çalışmalarında, farklı pürüzlü titanyum yüzeyler üzerinde oluşturulan biyofilm miktarı, Bevilacqua ve arkadaşları tarafından hem in vivo hem de in vitro olarak Konfokal Lazer Tarama Mikroskobu ile incelenmiştir. Çalışmaları, in vitro olarak geliştirilen biyofilmin, ağızdaki karmaşık toplulukların, çeşitli bakteri türlerinin, geniş bir aralıktaki besinlerin ve koşulların bakterilerin substrat kolonileşmesini optimize etmesine olanak sağlayarak oluşturduğu biyofilme göre yüzey özelliklerinden daha kolay etkilendiğini göstermiştir [11].

\section{Deneysel Çalışma}

İmplantların üretiminde el yapımı modelleme uygulanmıştır (Şekil 1). İmplantlar, alüminyum oksit inci tozu kullanılarak kumlama yöntemiyle, 1.5-3.0 bar basınç aralığı kullanılarak temizlenmiştir. Dental implantların fonksiyonelliğini tanımlayan pürüzlülük, ölçüm ile belirlenmiştir. Bu çalışmada hedef, klinik alanda hastalara uygulanacak en iyi yöntemi elde etmektir.
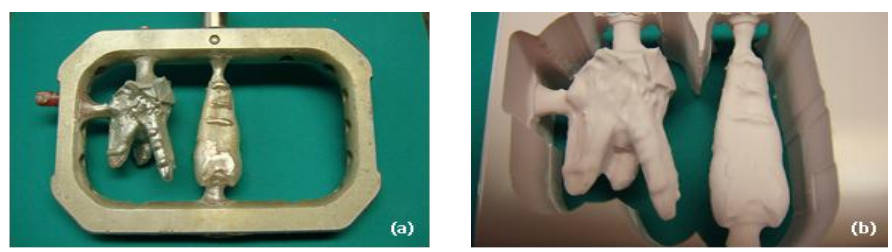

Şekil 1. İki implantın el ile hazırlanması (a) Balmumu modeli (b) Sinterlenmiş öğütülmüş zirkondioksit implantlar $[12,13]$.

Yüzeylerin mikromorfolojileri, BS EN ISO 4287:1998+A1:2009 standardına göre değerlendirilmiştir [14]. Bu çalışmada, 3B yüzeylerin topografik özelliklerini ölçebilmek için stylus profilometre ve 3B dijital mikroskop kullanılmıştır.

\section{1. Ölçme}

$\mathrm{Bu}$ deneysel çalışmanın temaslı yüzey pürüzlülük ölçümlerinde "Taylor Hobson" şirketine ait "Form Talysurf Intra 50" (Form Talysurf Intra) model cihaz kullanılmıştır. Cihaz $1 \mathrm{~mm}$ ölçme alanında $16 \mathrm{~nm}$ çözünürlüğe sahiptir. Dental bir örneğin pürüzlülük ölçümü sırasında görüntülenen cihazın fotoğrafı Şekil 2'de görülmektedir.

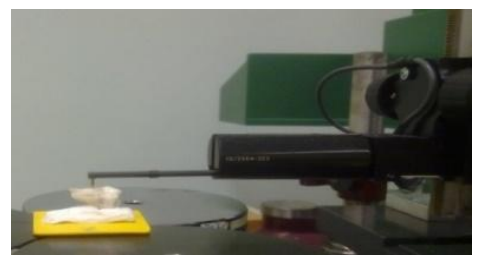

Şekil 2. Stylus profilometre ile dental numunenin ölçümü [15]. 
Dijital ölçümlerde, 3B dijital mikroskop (Keyence VHX-1000) kullanılmıştır. Şekil 3a ve 3b'de yüksek çözünürlüklü dijital mikroskoptan alınan orjinal diş \& implant numunelerinin görüntüleri verilmiştir.
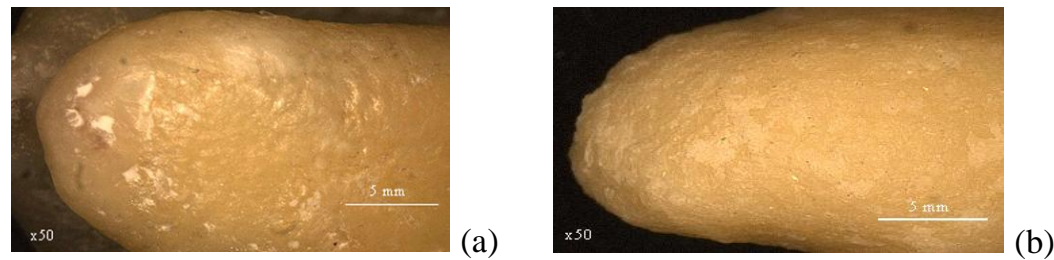

Şekil 3. Orijinal diş (a) ve İmplant örneği (b) [15].

\subsection{Görüntü İsleme}

Bu çalışmada, orjinal diş \& implant yüzeylerinin topografik analizleri, pürüzlülük ölçüm sonuçları ile yüksek çözünürlüklü 2B görüntülerinin Matlab görüntü işleme programında algoritmalar oluşturulmuş, görüntü işleme tekniği olan 2B Hızlı Fourier Dönüşümü (FFT) yardımıyla analiz edilmesini içermektedir. Bu deneysel çalışma kapsamında, orjinal diş \& implant yüzeylerinin yüksek çözünürlükte alınan görüntülerinin analizi için, numunelere ait görüntüler üç kısıma (kök, boyun ve taç) enlemesine bölümlenmiştir.

\subsection{Sinyal İşleme}

Frekans bileşenleri yüzey pürüzlülüğü hakkında birçok bilgi içermektedir. Zaman Bölgesi (time domain) ve Frekans Bölgesi (frequency domain) sinyalleri analiz edildiğinde yüzey pürüzlülüğü sonuçlarına ulaşmak mümkün olmaktadır. Bu çalışma, 1B FFT tekniği yardımıyla sinyallerin analiz edilmesini ve bu bağlamda pürüzlülükle ilişkilendirilmesini içermektedir.

\section{Bulgular}

\subsection{Yüzey Pürüzlüulük Ölçüm Bulgulart}

Orjinal diş \& implant örneği için, ISO standartlarına göre değerlendirme uzunluğu $4 \mathrm{~mm}$ ve örnekleme uzunluğu $0.8 \mathrm{~mm}$ olarak belirlenmiş, $0.8 \mathrm{~mm}$ uzun dalga boylu standart yüksek-geçirgen Gaussian filtre uygulanmıştır (BS EN ISO 4287:1998+A1:2009). Ölçümler beş (5) ölçüm noktas1 için, orjinal diş \& implant örneği üzerinde $1 \mathrm{~mm}$ aralıklarla tekrar edilmiştir. Stylus profilometreden profil diyagramları Şekiller 4 ve 5'de verilmiştir.

Yüzey topografisini değerlendirmek için orijinal diş \& implant örneğindeki kök, boyun ve taç bölümlerinden beşer kez ölçüm alınmıştır. Orijinal dişin yüzey pürüzlülüğü değerleri 5.37-9.46 $\mu \mathrm{m}$ aralığındadır. Bu çalışmada gerçekleştirilen incelemelerin sonucu olarak, orijinal diş için üretilen implantın yüzey yapısı itibarıyla orijinal dişe uygun olduğu sonucuna ulaşılmıştır. 


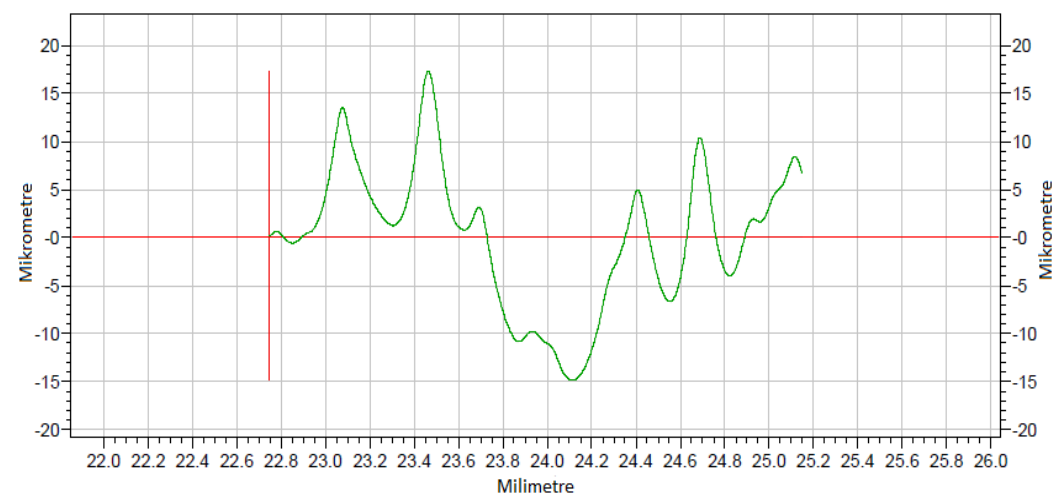

Şekil 4. Orjinal dişin boyun bölümünden alınan pürüzlülük profili $\left(R_{a}=5.75 \mu \mathrm{m}\right)[15]$.

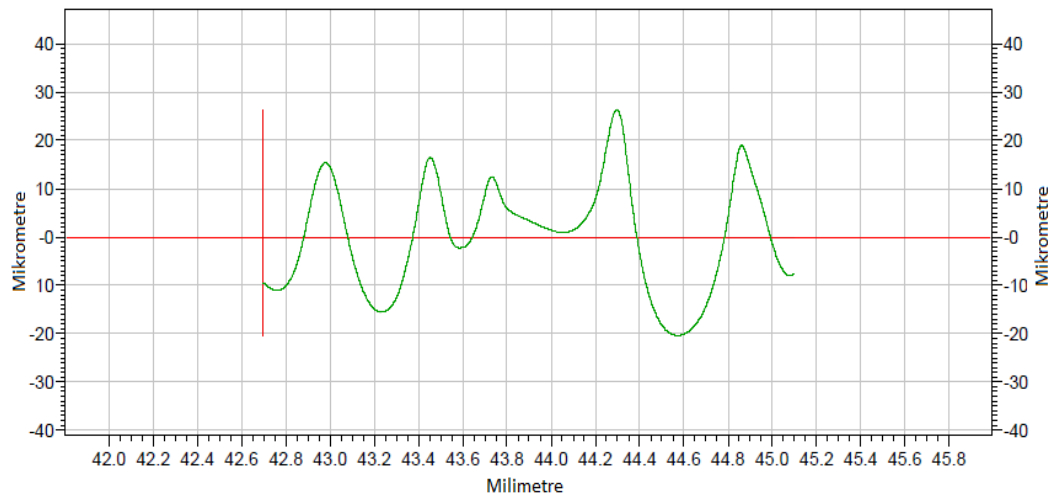

Şekil 5. İmplant örneğin boyu bölümünden alınan pürüzlülük profili $\left(R_{a}=9.36 \mu \mathrm{m}\right)[15]$.

Stylus profilometreden alınan yüzey pürüzlülüğü ölçüm sonuçları, Tablo 1'de gösterilmiştir.

Tablo 1. Yüzey pürüzlülüğü ölçüm sonuçları [15].

\begin{tabular}{ccccccc}
\hline \multicolumn{7}{c}{ Yüzey Pürüzlülüğü Ölçümleri $(\mu \mathrm{m})$} \\
\hline Ölçülen Parçalar & \multicolumn{2}{c}{ Kök } & \multicolumn{2}{c}{ Boyun } & \multicolumn{2}{c}{ Taç } \\
\hline & Diş & Implant & Dişs & Implant & Diş & İmplant \\
2 & 5.45 & 8.83 & 5.75 & 9.36 & 5.47 & 9.28 \\
3 & 5.41 & 9.00 & 5.76 & 9.39 & 5.46 & 9.36 \\
4 & 5.58 & 9.12 & 5.83 & 9.46 & 5.66 & 9.29 \\
5 & 5.52 & 9.20 & 5.84 & 9.30 & 5.58 & 9.28 \\
Ort & 5.63 & 9.27 & 5.89 & 9.19 & 5.55 & 9.21 \\
Std Sapma & 5.52 & 9.08 & 5.81 & 9.34 & 5.54 & 9.28 \\
\hline
\end{tabular}

Hastalar üzerinde başarılı tedavi sonuçları elde etmek için orijinal dişe benzer bir implant diş üretmek amaçlanmıştır. Bu yüzden, pürüzlülük ölçümü orijinal diş topografisini onun implant örneğiyle karşılaştırmak temel öneme sahiptir.

\subsection{Görüntü İşleme Bulguları}

Orijinal diş \& implanta ait FFT dönüşümü; kök, boyun ve taç kısımlarına ait görüntüler ile birlikte Tablo 2'de gösterilmiştir. Şekillerden açık bir şekilde görülebildiği üzere, yüzey pürüzlülüğü arttıkça, beyaz piksel alanının çapı azalmıştır. Şekiller 6 ve 7, FFT analizinin sonuçlarını göstermektedir. Regresyon denklemi ve siyah piksellerle yüzey pürüzlülüğü arasındaki ilişkiyi 
belirleyen katsayı (Şekil 6) Denklem (1) ile verilmiştir. Burada; y, siyah piksellerin sayısı; x ise yüzey pürüzlülüğüdür.

$\mathrm{y}=1966.8 \mathrm{x}+29464 \quad\left(R^{2}=0.94\right)$

Regresyon denklemi ve siyah pikseller ve yüzey pürüzlüğ̈ arasındaki ilişkinin belirleyen katsayı (Şekil 7), Denklem (2) ile verilmiştir. Burada; y, siyah piksellerin sayısı; x ise yüzey pürüzlülüğüdür.

$\mathrm{y}=1966.8 \mathrm{x}+29464 \quad\left(R^{2}=0.88\right)$

Tablo 2. Orijinal diş ve implant örneklere ait FFT dönüşümü yapılmış kök, boyun ve taç kısımlarının görüntüleri [15].

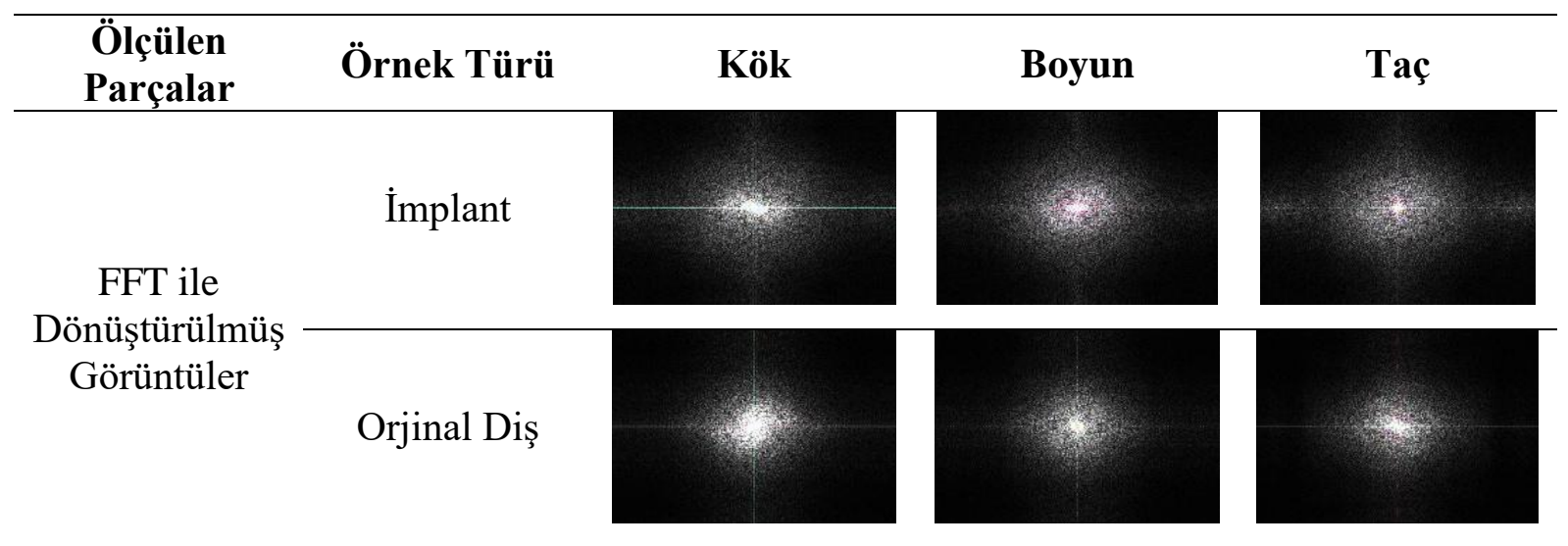

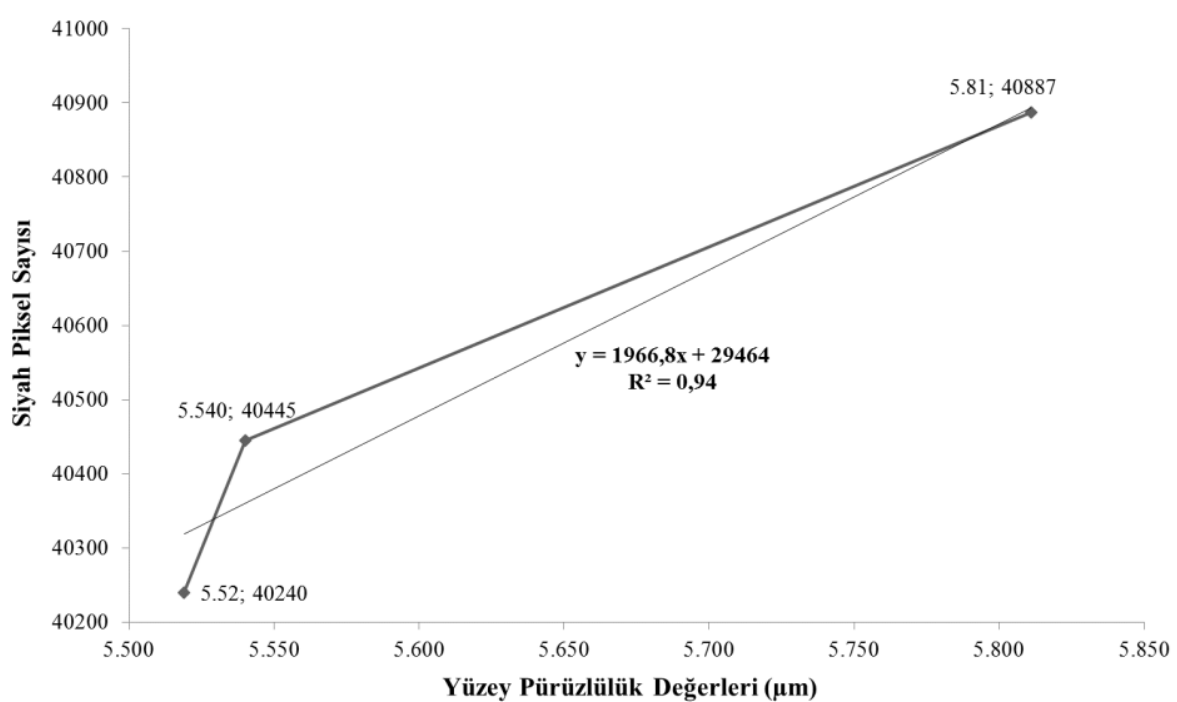

Şekil 6. Orijinal diş (kök, boyun ve taç) bölümlerinin görüntülerinden alınan FFT analizinden alınan siyah piksellerin sayısı [15].

Orjinal diş için, ölçüm hatalarının karelerinin ortalamasının karekökü (RMSE) değeri $0.033 \mu \mathrm{m}$ olarak hesaplanırken, implant için ise, $0.045 \mu \mathrm{m}$ olarak hesaplanmıştır. Bunun yanında, görüntü analizi sonuçları, FFT analizinin, yüksek korelasyonla (orjinal diş için, $R^{2}=0.94$ ve implant örnek için ise, $R^{2}=0.88$ ) yüzey pürüzlülüğündeki değişkenliği temsil edebileceğini göstermiştir. 


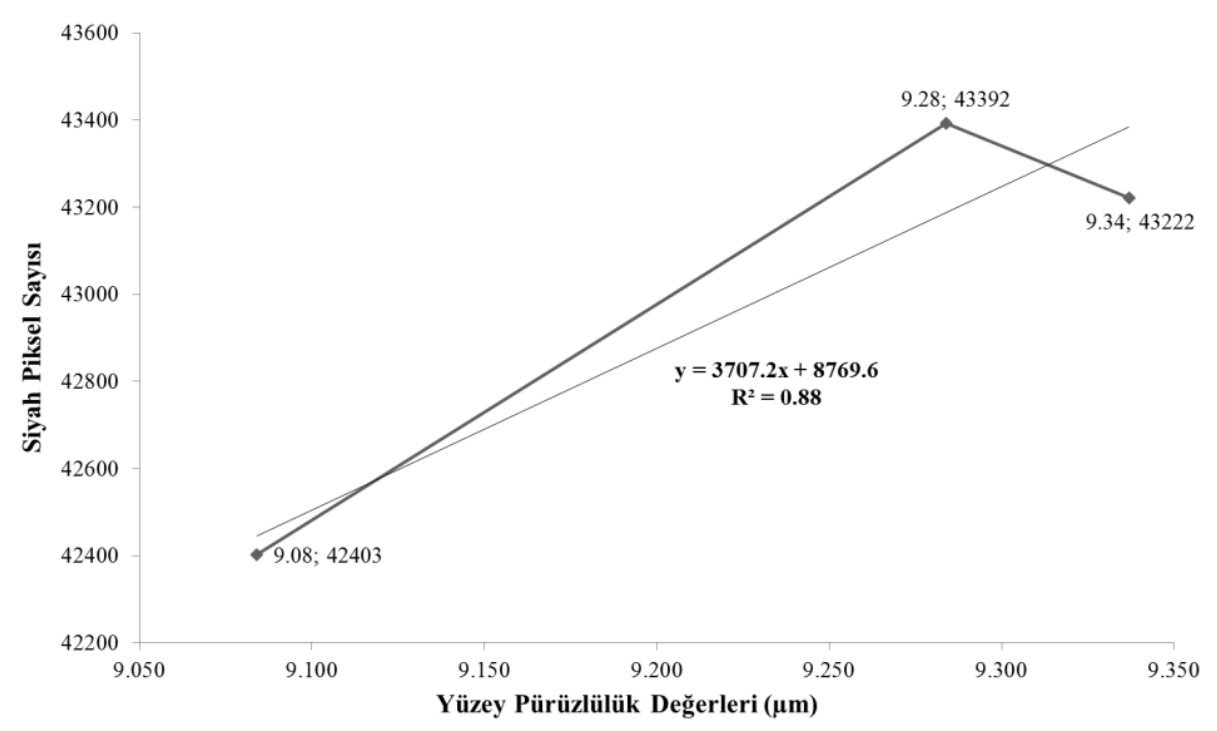

Şekil 7. İmplantın (kök, boyun ve taç) bölümlerinin görüntülerinden alınan FFT analizinden alınan

\subsection{Sinyal İşleme Bulgulart} siyah piksellerin sayıs1 [15].

Orijinal diş \& implanta ait FFT dönüşümü; kök, boyun ve taç kısımlarına ait görüntüler ile birlikte Tablo 2'de gösterilmiştir. Şekillerden açık bir şekilde görülebildiği üzere, yüzey pürüzlülüğü arttıkça, beyaz piksel alanının çapı azalmıştır. Şekiller 6 ve 7, FFT analizinin sonuçlarını göstermektedir.

Regresyon denklemi ve siyah piksellerle yüzey pürüzlülüğü arasındaki ilişkiyi belirleyen katsayı (Şekil 6) Denklem (1) ile verilmiştir. Burada; y, siyah piksellerin sayısı; x ise yüzey pürüzlülüğüdür.

$\mathrm{y}=1966.8 \mathrm{x}+29464 \quad\left(R^{2}=0.94\right)$

Regresyon denklemi ve siyah pikseller ve yüzey pürüzlüğü arasındaki ilişkinin belirleyen katsayı (Şekil 7), Denklem (2) ile verilmiştir. Burada; y siyah piksellerin sayısı; $x$ ise yüzey pürüzlülüğüdür.

$\mathrm{y}=1966.8 \mathrm{x}+29464 \quad\left(R^{2}=0.88\right)$

\section{Sonuç ve Öneriler}

Mevcut çalışmanın sınırları dâhilinde, bilgisayar görüntülerinin yüzey pürüzlülüğü parametrelerinin temassız ölçüm yoluyla belirlenmesinde büyük bir potansiyele sahip olduğu söylenebilir. 2B FFT görüntü işleme ve 1B FFT sinyal işleme sonuçları açık bir şekilde tekniğin yüzey pürüzlülük değerlendirilmesinde uygulanabilir olduğunu göstermektedir.

\section{Teșekkür}

$\mathrm{Bu}$ çalışma, Avusturya Federal Bilim ve Araştırma Bakanlığı tarafından desteklenmiştir. Bu çalışmadaki hassas ölçümler, Viyana Teknik Üniversitesi'nde; sinyal ve görüntü işleme analizleri ise, Adnan Menderes Üniversitesi Makine Mühendisliği Bölümü’nde gerçekleştirilmiştir. 


\section{Kaynaklar}

[1]. ISO International Organization for Standardization. "Quality management systems". Requirements for regulatory purposes. BS EN ISO 13485:2016 Medical devices, (2016).

[2]. ISO International Organization for Standardization. "Medical devices for dentistry". Dental implants. BS EN 1642: 2011 Dentistry, (2011).

[3]. ISO International Organization for Standardization. "Designation system for teeth and areas of the oral cavity". BS EN ISO 3950:2016 Dentistry, (2016).

[4]. ISO International Organization for Standardization. "Minimal dental implant data set for clinical use". BS EN ISO 16498: 2013 Dentistry, (2013).

[5]. Costa-Berenguer X., Garcia-Garcia M., Sanches-Torres A., Sanz-Alonso M., Figueiredo R. and Valmaseda-Castellon E., "Effect of implantoplasty on fracture resistance and surface roughness of standard diameter dental implants", Clinical Oral Implants Research, 2017, 29.

[6]. Rupp F., Liang L., Geis-Gerstorfer J., Scheideler L. and Hüttig F., "Surface characteristics of dental implants: A review", Dental Materials, 2018, 34, 40-57.

[7]. Babik O., Czan A., Holubjak J., Kamenik R. and Pilc J., "Identification of surface characteristics created by miniature machining of dental implants made of titanium based materials", Procedia Engineering, 2017, 192.

[8]. Kournetas N., Spintzyk S., Schweiser E., Sawada T., Said F., Schmid P., Geis-Gerstorfer J., Eliades G. and Rupp F., "Comparative evaluation of topographical data of dental implant surfaces applying optical interferometry and scanning electron microscopy”, Dental Materials, 2017, 33, 317-327.

[9]. Schmidt K.E., Auschill T.M., Heumann C., Frankenberger R., Eick S., Sculean A. and Arweiler, N.B., "Influence of different instrumentation modalities on the surface characteristics and biofilm formation on dental implant neck, in vitro", Clinical Oral Implants Research, 2017, 28, 483-490.

[10]. Bosshardt D.D., Chappuis V. and Buser D., "Osseointegration of titanium, titanium alloy and zirconia dental implants: current knowledge and open questions", Periodontology 2000, 2017, 73, 22-40.

[11]. Bevilacqua L., Milan A., Del Lupo V., Maglione M., Dolzani L., "Biofilms Developed on Dental Implant Titanium Surfaces with Different Roughness: Comparison Between In Vitro and In Vivo Studies", Current Microbiology, 2018.

[12]. M.N. Durakbasa, P. Demircioglu, G. Bas, W. Pirker, "Micro-examination of Dental Samples to enable the Quality Characteristics required by the Clinical Experience using Biomedical Metrology", MicroCAD, Miskolc, Hungary, (2012).

[13]. Pirker W, Kocher A., "Immediate, non-submerged, root-analogue zirconia implant in single tooth replacement", Int J. of Oral and Maxillofacial Surgery, 2008, 37, 293-295.

[14]. ISO International Organization for Standardization. "Surface texture: Profile method". Terms, definitions and surface texture parameters. BS EN ISO 4287: 1998 + A1:2009 Geometrical product specification (GPS), (2009).

[15]. Demircioglu P., "Estimation of Surface Topography for Dental Implants using Advanced Metrological Technology and Digital Image Processing Techniques”, Measurement, 2014. 